\section{đoán UTTTL.}

Trong tổng số 84 BN chúng tôi sinh thiết, có $28 \mathrm{BN}$ gặp biến chứng trong và sau thủ thuật $(33,3 \%)$, chảy máu hậu môn $(17,8 \%)$, tiểu máu (14,2\%), sốt (1 trường hợp), có 1 bệnh nhân gặp nhiểm khuẩn tầng sinh môn, không gặp các biến chứng xuất tinh ra máu. Tai biến gặp chủ yếu là chảy máu hậu môn ở mức độ nhẹ và chỉ cân đặt meche cầm máu và rút meche sau một ngày máu tự cầm không cần phải xử trí thêm. Các $B N$ tiểu máu sau sinh thiết, nước tiểu màu hồng, được theo dõi sát sau hai ngày thì tự cầm. BN có dâu hiệu đau tầng sinh môn hoặc sốt $(37,8$ $\left.38,5^{\circ} \mathrm{C}\right)$, được chúng tôi xử trí bằng kháng sinh tĩnh mạch, hạ sốt đường uống thì hết sốt và giảm đau sau một ngày. Có thể thấy ${ }_{\ell}$ các tai biến này đều ở mức đô nhe, có thể dế dàng khắc phục hoặc tự khỏi. Kết quả này phù hợp với các nghiên cứu trước $\mathrm{c}^{7,8}$, từ đó khẳng định tính an toàn của sinh thiết tuyến tiền liệt dưới hướng dẫn siêu âm qua trực tràng.

\section{KẾT LUẬN}

STTTL dưới hướng dẫn của siêu âm qua trực tràng là một thủ thuật có độ chính xác cao (độ nhạy và độ đặc hiệu là $93.8 \%$ và $82,8 \%$ ), đồng thời cũng khá an toàn, ít biến chứng với hâu hết các biến chứng đều ở mức độ nhẹ.

\section{TÀI LIÊU THAM KHẢO}

1. Sung $H$, Ferlay $J$, Siegel $R L$, Laversanne $M$, Soerjomataram I, Jemal A, Bray F. Global Cancer Statistics 2020: GLOBOCAN Estimates of Incidence and Mortality Worldwide for 36 Cancers in 185 Countries. CA Cancer J Clin. 2021 May;71(3):209-249. doi: 10.3322/caac.21660. Epub 2021 Feb 4. PMID: 33538338.

2. Bruyerre.F, O. Traxer (2005), "Prise en charge du cancer de la prostate". Annales d'Urologie. ( Vol 39/suppl.1, Pg 1-16).

3. J.Stephen Jone, MD (2008), "Definin the problem: From subclinical disease to clinically insignifcant prostate cancer". Prostate byopsy. Chapter 1, pp $16-17$.

4. Lê Ngoc Bằng (2005), "Vai trò cửa sinh thiết kết hợp với PSA và siêu âm trong chẩn đoán UTTTL" Đề tài thạc sĩ y học ngoại khoa.

5. Khoury.s (1998), "Lés stades du cancer de la prostate" (Pg167), " Diagnostic du cancer de la prostate"(Pg179). Urologie - Cancer de la prostate.

6. Joe Philip, Subhajit Dutta Joy and al (2005), "Is a Digital Rectal Examination Necessary in the Diagnosis and Clinical Staging of Early Prostate Cancer", BJU International, 95, Pg 969-971.

7. Terris M.K (1999), "Sensitivity and specificity of sextant biopsies in the detection of prostate cancer: preliminary report".Urology. Sep;54(3):486-9.

8. Epstein JI, Sanderson H, Carter HB, Schafstein DO (2005)."Utility of saturation biopsy to predict insignificant cancer at radical prostatectomy". Urology. Aug; 66(2):356-60.

\title{
ĐÁNH GIÁ KẾT QUẢ BƯớC ĐẦU ĐIỀU TRI UNG THƯ BIỂU MÔ TẾ BÀO GAN BẰNG PHƯƠNG PHÁP NÚT MẠCH SỬ DƯNG CỒN TUYÊTT ĐỐI VÀ LIPIODOL
}

\author{
Nguyễn Duy Thịnh', Bùi Văn Giang,3, Phạm Thế Anh ${ }^{4}$,
} Vũ Lê Minh ${ }^{3}$, Nguyễn Quang Toàn ${ }^{3}$,

\section{TÓM TẮT}

Mục tiêu: Nghiên cứu nhằm đánh giá kết quả điều trị ung thư biểu mô tế bào gan bằng phương pháp nút mạch sử dụng cồn tuyệt đối và lipiodol. Đối tượng và phương pháp: Nghiển cứu được thực hiện trên 33 bệnh nhân ung thư biểu mô tế bào gan được nút mạch bắng côn tuyệt đối và lipiodol tại bệnh viện $\mathrm{K}$ cơ sở

\footnotetext{
${ }^{1}$ Bênh viện Thanh Nhàn

2Trường Đại hoc Y Hà Nội

${ }^{3}$ Trung tâm Chẩn đoán hình ảnh, Bệnh viện $K$ cơ sở Tân Triều

${ }^{4}$ Trung tâm Gan-Mật-Tưy, bệnh viện K cơ sở Tân Triều

Chịu trách nhiệm chính: Nguyễn Duy Thịnh

Email: saithanhvagabond2008@gmail.com

Ngày nhận bài: 4.6.2021

Ngày phản biên khoa hoc: 29.7.2021

Ngày duyệt bài: 6.8 .2021
}

Tân Triều từ tháng 03/2020 đến tháng 06/2021. Tiến hành tính và so sánh tỳ lệ đáp ứng điều trị sau can thiệp 01 và 03 tháng giữa 2 nhóm u có kích thước $\leq$ $10 \mathrm{~cm}$ và $>10 \mathrm{~cm}$, nhóm can thiệp sử dụng $E: L ~ 1: 1$ và $1: 2$. Theo dõi sư thay đổi nồng đô aFP sau can thiêp 01 tháng và 03 tháng. Kết quả: Tỷ lệ đáp ứng điều trị nhóm u có kích thước $\leq 10 \mathrm{~cm}$ cao hơn nhóm kích thước $u>10 \mathrm{~cm}(p<0,005)$, nhóm có tỷ lệ $E: L 1: 1$ cao hơn nhóm $E: L 1: 2(p<0,005)$. Nồng độ aFP giảm dân sau can thiệp 01 tháng và 03 tháng $(p<0,001)$. Kết luận: Điều trị UTBMTBG bằng TAELE là một phương pháp an toàn và hiệu quả cần được nghiên cứu thêm để đánh giá đầy đủ.

Tư khóa: Ung thư biểu mô tế bào gan, TAELE.

\section{SUMMARY \\ ASSESSMENT OF INITINAL TREATMENT \\ RESULTS HEPATOCELLULAR CARCINOMA BY METHOD EMBOLIZATION USING}


ETHANOL AND LIPIODOL

Purpose: The study aimed to evaluate the results of hepatocellular carcinoma treatment by embolization using ethanol and lipiodol. Material and Methods: The study was carried out on 33 patients with hepatocellular carcinoma who were embolized with ethanol and lipiodol at K Hospital from march 2020 to june 2021. Conducting calculate and compare the rate of treatment response after 01 and 03 months of intervention between 2 groups of tumors with size $\leq$ $10 \mathrm{~cm}$ and $>10 \mathrm{~cm}$, the intervention group used $\mathrm{E}: \mathrm{L}$ $1: 1$ and $1: 2$. Monitoring the change in aFP levels after 01 and 03 months of intervention. Results: The rate of response to treatment was higher in the group with tumor size $\leq 10 \mathrm{~cm}$ than in the group with tumor size $>10 \mathrm{~cm}(p<0.005)$, the group with the ratio E:L $1: 1$ was higher than the group $E: L 1: 2(p<0.005)$. ). The concentration of aFP gradually decreased after the intervention 01 and 03 months $(p<0.001)$. Conclusion: Treatment of HCC with TAELE is a safe and effective method that needs further study for its full evaluation.

Keywords: hepatocellular carcinoma, TAELE

\section{I. ĐẶT VẤN ĐỀ}

UTBMTBG

Hepatocellular

carcinoma

(UTBMTBG) là môtt trong những ung thư phổ biến nhất trên thế giới. Ở các nước đã phát triển UTBMTBG được xếp vào hàng thứ 14 , số mới mắc hàng năm là 59.600. Trái lại, ở các nước đang phát triển, hàng năm phát hiện thêm 191.600 người, xếp hàng thứ 7. Ở Nhật Bản và Senegan tỷ lệ mới mắc UTBMTBG nguyên phát trên 100.000 dân là 11,2 và 25,6 nhưng ở Đan Mạch chỉ là 3,6/100.000. Tổng chung lại, ung thư gan xếp hàng thứ 8 [1]. Người ta cũng nhận thấy UTBMTBG gặp ở nam nhiêu hơn ở nữ.

Việt Nam đang đứng thứ 2 về số ca mắc ung thư gan. ở nam giới, tỷ lệ ung thư gan nguyên phát đứng hàng đầu Hồ Chí Minh và đứng thứ 3 ở Hà Nội. Bệnh diễn biến nhanh và có tiên lượng xấu nếu khổng được phát hiện và điều trị sớm. Cho đến nay có nhiều phương pháp điều trị ung thư biểu mô tế bào gan như: cắt gan, ghép gan, thắt động mạch gan, phóng xạ, hóa chất, tiêm cồn vào khối u, đốt nhiệt cao tần, nút mạch khối u... tùy thuộc vào từng giai đoạn bệnh. Nút mạch hóa chất là một phương pháp điều trị tạm thời cơ bản nhằm kéo dài thời gian sống cho các trường hợp UTBMTBG không còn chỉ định phẫu thuật. Các phương pháp CTACE và DEB- TACE với kích cõ̃ hạt nhỏ, khả năng gắn được hàm lượng hoá chất cao có hiệu quả tốt đối với khối u có kích cõ nhỏ, các khối u lớn với nhiêu nguồn nuôi phương pháp này cần phải tiến hành nhiều lần, chi phí điều trị cao. Cồn tuyệt đối (Ethanol 96\%) gây mất nước cấp làm nguyên sinh chất tế bào bi đông vón dẫn đến xơ hoá và xâm nhập vào mạch máu gây hoại tử tế bào nội mạc, vì vậy có tác dụng gây hoại tử khối u trên diện rộng và nhanh chóng. Nút mạch sử dụng vật liệu là cồn tuyệt đối và lipiodol (Transarterial ethanol and lipiodol embolization - TAELE) là phương pháp nút mạch cải tiến, an toàn và chi phí thấp, đã được áp dụng ở nhiều nước trên thế giới đặc biệt là với các khối u gan lớn. Tuy nhiên ở Việt Nam mới chỉ có một số bệnh viện lớn bắt đầu triển khai ứng dụng phương pháp này trong điêu trị UTBMTBG. Hiên tại ở Việt Nam chưa có nghiên cứu nào về giá trị của phương pháp nút mạch UTBMTBG bằng vật liệu cồn tuyệt đối và lipiodol. Vì vậy chúng tôi tiến hành đề tài: "Đánh giá kết quả bước đầu điều trị ung thư biểu mô tế bào gan bằng phương pháp nút mạch sử dụng cồn tuyệt đối và lipiodol"

\section{II. ĐỐl TƯỢNG VÀ PHƯƠNG PHÁP NGHIÊN CỨU}

1. Đối tượng nghiên cứu. Gồm $33 \mathrm{BN}$ được chẩn đoán xác định là ung thư biểu mô tế bào gan được điều trị nội trú tại bệnh viện $\mathrm{K}$. Thời gian nghiên cứu từ tháng 03/2020 đến tháng 06/2021.

2. Phương pháp nghiên cứu. Nghiên cứu mô tả cắt ngang, thu thập số liệu hồi cứu và tiến cứu. Với 33 BN có 33 khối u đường kính $\geq 7 \mathrm{~cm}$ ( $5 \mathrm{BN}$ chẩn đoán bằng sinh thiết và làm giải phẫu bệnh, $28 \mathrm{BN}$ chẩn đoán dựa vào hình ảnh và chất chỉ điểm aFP theo tiêu chuẩn của Bộ Y Tế). Có 21 khối u được điều trị bằng hỗn hợp Cồn tuyệt đối và Lipiodol theo tỷ lệ $1: 1$ và $12 \mathrm{BN}$ điều trị bằng tỷ lệ $1: 2$. Các tác dụng phụ và đáp ứng điều trị được đánh giá sau 1 tháng và 3 tháng.

Sử dụng tiêu chuẩn mRECIST (modified Response Evaluation Criteria in Solid Tumors) của Hiệp hội Gan mật châu Âu (EASL) dựa vào mức độ ngẩm thuốc của mô u trên phim chụp CLVT có tiêm thuốc cản quang để xác định mức độ đáp ứng điều trị. Có 4 mức độ đáp ứng điều trị: đáp ứng hoàn toàn $(C R)$, đáp ứng một phần $(P R)$, bệnh ổn định $(S D)$ và bệnh tiến triển (PD).
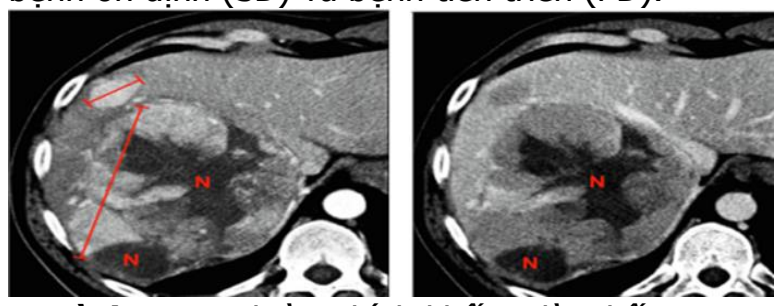

Hình 1: Đo đường kính khối u dài nhất trong gan đích không bị hoại tử (vùng ngấm thuốc cản quang) theo mRECIST

3. Xử lý và phân tích số liệu. Số liệu được nhập và phân tích bằng phần mềm SPSS 20.0. 
Tính tỷ lệ \% cho các biến định tính, tính giá trị trung bình và độ lệch chuẩn (SD) cho các biến định lượng liên tục. Sử dụng kiểm định Chi Square để so sánh đánh giá đáp ứng khối u theo kích thước và tỷ lệ $E: L$, có ý nghĩa thống kê với $\mathrm{p}<0,05$.

\section{KẾT QUẢ NGHIÊN CỨU}

1. Đặc điểm đối tượng nghiên cứu. Trong thời gian từ tháng $3 / 2020$ đến tháng $6 / 2021$, có
$33 \mathrm{BN}$ ung thư biểu mô tế bào gan có tuổi trung bình là 54,42 14,48 tuổi, độ tuổi từ 19 đến 71 tuổi, nhóm tuổi hay gặp nhất 40-60 tuổi, tỉ lệ nam:nũ là $3,7: 1$. Yếu tố nguy cơ nhiễm virus viêm gan $B$ chiếm tỷ lệ cao $72,73 \%$. Phần lớn các $B N$ xơ gan Child - Pugh $A(87,88 \%)$ và đến khám với triệu chứng đau hạ sườn phải là phổ biến nhất $(54,55 \%)$. $33 \mathrm{BN}$ với 33 khối u, kích thước trung bình của khối u là 10,82 $\pm 2,48 \mathrm{~cm}$, các khối u chủ yếu nằm ở gan phải $90,91 \%$.

\section{Sự thay đổi nồng độ aFP sau điêu trị}

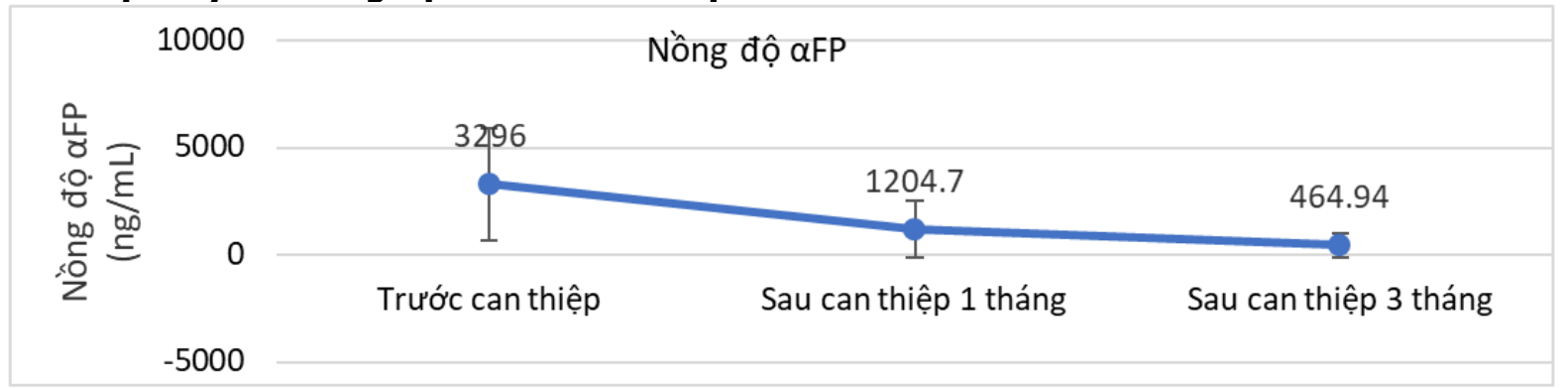

\section{Biểu đồ 1. Thay đổi nông độ aFP theo thời gian $(n=33)$}

Trong nhóm NC, có sự giảm nồng độ $\mathrm{aFP}$, tữ mức 3296,00 ng/mL trước can thiệp, xuống còn $1204,70 \mathrm{ng} / \mathrm{mL}$ và $464,94 \mathrm{ng} / \mathrm{mL}$ sau can thiệp 01 tháng và 03 tháng. Sự giảm này là có ý nghĩa thống kê, $\mathrm{p}<0,001$.

\section{3. Đánh giá đáp ứng điêu trị theo mRECIST}

\section{Bảng 1. Đánh giá đáp ứng điều trị theo mRECIST ( $n=33)$}

\begin{tabular}{|c|c|c|c|c|c|c|c|}
\hline \multicolumn{2}{|c|}{ Thời gian } & \multicolumn{3}{c|}{ Đáp ứng điều trị } & \multicolumn{3}{c|}{ Không đáp ứng điêu trị } \\
\cline { 2 - 8 } & CR & PR & Tống & SD & PD & Tống \\
\hline \multirow{2}{*}{ tháng } & $\mathrm{n}$ & 5 & 23 & 28 & 3 & 2 & 5 \\
\cline { 2 - 8 } & $\%$ & 15,15 & 69,70 & 84,85 & 9,09 & 6,06 & 15,15 \\
\hline \multirow{2}{*}{ tháng } & $\mathrm{n}$ & 3 & 24 & 27 & 2 & 4 & 6 \\
\cline { 2 - 8 } & $\%$ & 9,09 & 72,73 & 81,82 & 6,06 & 12,12 & 18,18 \\
\hline
\end{tabular}

Sau 1 tháng điêu tri, có $28 / 33$ BN có đáp ứng với điêu tri, chiếm tỷ lê 84,85\%. Trong đó, có $05 / 33$ BN đáp ứng hoàn toàn, chiếm $15,15 \%$ tổng số BN. Sau 3 tháng, tỷ lệ BN đáp ứng với điều trị giảm xuống còn $81,82 \%$.

4.Đánh giá đáp ứng điêu trị theo kích thước khối u và tỷ lệ E:L

\section{Bảng 2. So sánh đáp ứng khối u theo kích thước u (n=33)}

\begin{tabular}{|c|c|c|c|c|c|c|}
\hline \multirow{2}{*}{$\begin{array}{l}\text { Thời } \\
\text { gian }\end{array}$} & \multirow{2}{*}{ Kích thước u } & \multicolumn{2}{|c|}{ Đáp ứng điêuu trị } & \multicolumn{2}{|c|}{ Không đáp ứng điều trị } & \multirow[b]{2}{*}{$\mathbf{p}$} \\
\hline & & $n$ & $\%$ & $n$ & $\%$ & \\
\hline \multirow{3}{*}{1 tháng } & $\leq 10 \mathrm{~cm}$ & 15 & 100 & 0 & 0 & \multirow{3}{*}{$<0,05$} \\
\hline & $>10 \mathrm{~cm}$ & 13 & 72,2 & 5 & 27,8 & \\
\hline & Tống & 28 & 84,8 & 5 & 15,2 & \\
\hline \multirow{3}{*}{3 tháng } & $\leq 10 \mathrm{~cm}$ & 15 & 100 & 0 & 0 & \multirow{3}{*}{$<0,05$} \\
\hline & $>10 \mathrm{~cm}$ & 12 & 66,7 & 6 & 33,3 & \\
\hline & Tống & 27 & 81,8 & 6 & 18,2 & \\
\hline
\end{tabular}

Tất cả các $B N$ có khối u $<10 \mathrm{~cm}$ đều đáp ứng điều trị sau can thiệp $01 v a ̀$ à 03 tháng. Các trường hợp không đáp ứng điêu trị là các $B N$ có $u>10 \mathrm{~cm}$. Có sự tương quan giữa kích thước khối u và sự đáp ứng điều trị ở thời điểm 01 tháng và 03 tháng. Khối u càng nhỏ đáp ứng điêu trị càng tốt. Sự khác biệt là có ý nghĩa thống kê, $\mathrm{p}<0,05$.

Bảng 3. So sánh đáp ứng khối u trên các tỷ lệ E:L $(n=33)$

\begin{tabular}{|c|c|c|c|c|c|c|}
\hline \multirow{2}{*}{$\begin{array}{l}\text { Thời } \\
\text { gian }\end{array}$} & \multirow{2}{*}{$\begin{array}{l}\text { Tỷ lề } \\
\text { E/L }\end{array}$} & \multicolumn{2}{|c|}{ Đáp ứng điều trị } & \multicolumn{2}{|c|}{ Không đáp ứng điêu trị } & \multirow[b]{2}{*}{$\mathbf{P}$} \\
\hline & & $\mathrm{n}$ & $\%$ & $n$ & $\%$ & \\
\hline 1 & $1: 1$ & 21 & 100 & 0 & 0 & $<0,05$ \\
\hline
\end{tabular}




\begin{tabular}{|c|c|c|c|c|c|c|}
\hline tháng & $1: 2$ & 7 & 58,3 & 5 & 41,7 & \\
\cline { 2 - 6 } & Tống & 28 & 84,8 & 5 & 15,2 & \\
\hline \multirow{3}{*}{3} & $1: 1$ & 21 & 100 & 0 & 0 & \\
\cline { 2 - 6 } tháng & $1: 2$ & 6 & 50 & 6 & 50 & \\
\cline { 2 - 6 } & Tống & $\mathbf{2 7}$ & $\mathbf{8 1 , 8}$ & $\mathbf{6}$ & $\mathbf{1 8 , 2}$ & \\
\hline
\end{tabular}

Trong nhóm $\mathrm{BN}$ được nút mạch với tỷ lệ $\mathrm{E} / \mathrm{L}$ là 1:1, $100 \%$ BN đáp ứng với điều trị. Trong số $12 \mathrm{BN}$ nút mạch với tỷ lệ $\mathrm{E} / \mathrm{L}=1: 2$, sau 1 tháng có $5 \mathrm{BN}$ không đáp ứng điêuu trị, sau 3 tháng có $6 \mathrm{BN}$. Sự khác biệt này là có ý nghĩa thống kê, $p<0,05$.

\section{Hội chứng sau tắc mạch}

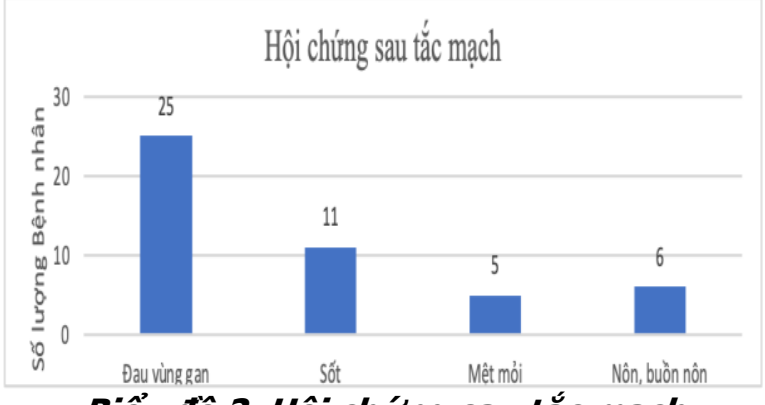

Biếu đồ 2. Hội chứng sau tắc mạch

Triệu chứng hay gặp nhất sau can thiệp là đau vùng gan, chiếm tỷ lệ $75,76 \%$.

\section{BÀN LUẬN}

Trong nghiên cứu của chúng tôi, độ tuổi trung

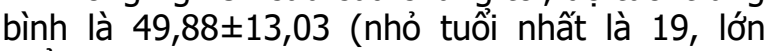
tuổi nhất là 71). Kết quả này tương tự với kết quả của tác giả Phùng Anh Tuấn, tuổi trung bình là $54,42 \pm 14,48$ (nhỏ tuổi nhất 35 , lớn tuổi nhất 72) [2]. Trong nghiên cứu của chúng tôi tỷ lệ nam trên nữ là 3,7 , số lượng $B N$ nhiễm virus viêm gan $B$ chiếm tỷ lệ cao là $72,73 \%$. Tỷ lệ này của chúng tôi gần giống với Lê Anh Tuấn tỷ lệ nam trên nữ là 4 , BN nhiễm virus viêm gan $B$ chiếm tỷ lê $76,9 \%$ [3].

UTBMTBG thường không có triệu chứng rõ ràng, tiến triển thầm lặng, thường xuất hiện khi bệnh ở giai đoạn muộn. Kết quả nghiên cứu của chúng tôi cho thấy rằng triệu chứng đau hạ sườn phải là phổ biến nhất chiếm tỷ lệ $54,55 \%$ và sút cân chiếm $15,5 \%$. Kết quả nghiên cứu này phù hợp với tác giả Phạm Trung Dũng [4]. Kết quả nghiên cứu của chúng tôi cho thây rắng phần lớn BN là xơ gan Child-Pugh A $(87,88 \%)$, xơ gan Child-Pugh $B$ chiếm tỷ lệ thấp $(12,12 \%)$. Chỉ số toàn trạng 0 chiếm đa số $(66,67 \%)$, chỉ số toàn trạng 1 tỷ lệ $27,27 \%$. Điều này có thể được giải thích trong tiêu chuẩn lựa chọn các BN nghiên cứu có chức năng gan tốt.

Phần lớn các khối u trong nghiên cứu của chúng tôi có kích thước lớn hơn $10 \mathrm{~cm}(54,5 \%)$, kích thước khối u trung bình là 10,82 $22,48 \mathrm{~cm}$. Theo nghiên cứu của tác giả Dương Minh Thắng, thực hiện C-Tace trên 72 BN được chia thành 3 nhóm dựa trên kích thước khối u bao gồm 3$5 \mathrm{~cm}, 5-10 \mathrm{~cm}$ và $>10 \mathrm{~cm}$, thời gian sống trung bình tương ứng là 19,8 1,8 tháng, $22,5 \pm 2,5$ tháng và $16,9 \pm 1,3$ tháng. Sự khác biệt về thời gian sống giữa 2 nhóm $u \leq 10 \mathrm{~cm}$ và $>10 \mathrm{~cm}$ có ý nghĩa thống kê $(p<0,05)$ [5]. Nghiên cứu của chúng tôi cho thấy giá trị aFP sau can thiệp đã giảm đáng kể so với trước khi can thiệp. Nồng độ thấp nhất $2,8 \mathrm{ng} / \mathrm{ml}$ và nồng độ tối đa 185412 $\mathrm{ng} / \mathrm{ml}$. Kết quả này tương đương với nghiên cứu của El Wakeel (2016), giá trị trung bình của aFP trước điều trị là $808,11 \pm 545,14 \mathrm{ng} / \mathrm{ml}$, biên độ dao động rất rộng $(52 \mathrm{ng} / \mathrm{ml}$ đến $100000 \mathrm{ng} / \mathrm{ml})$. Giá trị aFP trung bình giảm đáng kể sau khi điều trị và thấp nhất được quan sát ở tháng thứ 3 sau điều trị $(p<0,001)[6]$.

Nghiên cứu của chúng tôi cho thấy sự đáp ứng hoàn toàn và một phần của khối u sau 01 tháng và 03 tháng chiếm tỷ lệ cao lần lượt là $84,85 \%$ và $81,82 \%$. Kết quả này phù hợp với kết quả nghiên cứu của tác giả Yang Kui Gu (2010) trên $15 \mathrm{BN}$, được chia làm hai nhóm mới điêu trị và đã điều trị bằng phương pháp nút mạch khác, cả hai nhóm cho thấy tỷ lệ đáp ứng hoàn toàn và một phần là 73,33\% [7]. Somma (2015) thực hiển nghiên cứu trên 45 bệnh nhân cho thấy tỷ lê đáp ứng hoàn toàn và một phần lên tới $100 \%$ [8]. Tỷ lệ đáp ứng một phần trong nghiên cứu của chúng tôi sau 01 tháng và 03 tháng là $69,7 \%$ và $72,73 \%$. Kết quả này tương tự với kết quả của tác giản Yang Kui Gu (2010) với tỷ lệ đáp ứng một phần cao nhất là $60 \%$ [7]. Tỷ lệ đáp ứng một phần sau điều trị 01 tháng và 03 tháng của El Wakeel là $8,4 \%$ và $12,5 \%$ [6]. Điều này được giải thích do kích thước lớn của khối u, cần phải cân bằng giữa việc sử dụng lượng côn tuyệt đối và tránh các biến chứng về độc tính của cồn. Nhóm đáp ứng hoàn toàn trong nghiên cứu của chúng tôi giảm theo thời gian lần lượt là 15,15\% và $9,09 \%$ tại thời điểm 01 và 03 tháng. Điêu này được giải thích là do kích thước của các khối u lớn, sự đáp ứng điều trị chỉ là tạm thời, cần phải nút tắc động mạch nhiều lần hoặc kết hợp các phương pháp khác để đạt hiệu quả tốt nhất sau điều trị. Tỷ lệ bệnh tiến triển tháng 01 và 03 sau 
điều trị là 6,06\% và 12,12\%. Yu (2014) công bố tỷ lệ bệnh tiến triển sau 03 tháng điêu trị bằng TAELE $(9 \%)$ thấp hơn so với cTACE $(27 \%), p=$ 0,027 [9]. Hiêu quả của TAELE đã được so sánh với cTACE. Yu đã làm sáng tỏ bằng cách quan sát các bệnh nhân và sau đó nhận ra rằng tỷ lệ đáp ứng hoàn toàn liên tục và cao hơn đáng kể với TAELE so với cTACE sau 01 tháng (70\% so với $51 \%, \mathrm{p}=0,012)$ và sau 03 tháng $(73 \%$ so với $54 \%, p=0,012$ )[9]. Tỷ lệ đáp ứng hoàn toàn và tỷ lệ đáp ứng hoàn toàn/đáp ứng một phần thời điểm 03 tháng ở nhóm TAELE cao hơn nhóm cTACE (60\% so với $38 \%, p=0,035,69 \%$ so với $49 \%, p=0,043)[9]$.

Trong nghiên cứu của chúng tôi có mối quan hệ giữa sự đáp ứng điều trị và kích thước khối u ở tháng thứ 01 và 03 sau điều trị $(p<0,05$, kiểm định Chi - Square). Trong đó nhóm u kích thước $\leq 10 \mathrm{~cm}$ tỷ lệ đáp ứng điêuu trị cao hơn nhóm u kích thước > $10 \mathrm{~cm}(100 \%$ so với $72,2 \%$ thời điểm 01 tháng và $100 \%$ so với $66,7 \%$ thời điểm 03 tháng). Dương Minh Thắng (2008) làm rõ sự khác biệt về đáp ứng điều trị và thời gian sống thêm giữa các nhóm u dưới $10 \mathrm{~cm}$ và trên $10 \mathrm{~cm}$ là có ý nghĩa thống kê $(p<0,05)[5]$. Điều này có thể được giải thích do các khối u có kích thước lớn được nuôi dưỡng bởi nhiều nhánh động mạch, cần phải sử dụng lượng lớn cồn tuyệt đối và lipiodol. Vì độc tính nên cân nhắc không dùng quá liều lượng cho phép, do đó các khối u lớn cần phải thực hiện điều trị nhiều lần.

Trong nghiên cứu của chúng tôi tỷ lệ đáp ứng điều trị ở nhóm $\mathrm{E}: \mathrm{L}(1: 1)$ cao hơn nhóm $\mathrm{E}: \mathrm{L}$ (1:2) ở thời điểm 01 tháng và 03 tháng $(100 \%$ so với $58,3 \%$ và $100 \%$ so với $50 \%)(p<0,05)$. Kết quả này phù hợp với các kết quả nghiên cứu của tác giả Gu (2010) [7]. Điều này được giải thích đối với các UTBMTBG đơn độc, tỷ lệ côn tuyệt đối tương đối thấp $(1: 3$ hay $1: 2)$ là thích hợp vì các khối u có kích thước nhỏ, có vỏ và được cấp máu chủ yếu từ động mạch gan, với ít thông động mạch gan và tĩnh mạch cửa. Tổn thương các mạch máu nhỏ là khá nhe vì tỷ lệ cồn trong hỗn hợp thấp hơn và do đó nhiều hỗn hợp lắng đọng hơn bên trong khối u. Nó giúp hỗn hợp được lưu giữ lâu hơn trong các tế bào khối u để tạo ra tác dụng chống khối u. Đối với các khối u lớn có nhiều thông động mạch gan và tĩnh mạch cửa, phải tiến hành nút tắc mạch nhiều lần, sử dụng cồn tuyệt đối với tỷ lệ cao hơn sẽ giúp ngăn chặn hiệu quả nguồn cấp máu từ động mạch gan và tĩnh mạch cửa [7]. Trong nghiển cứu của chúng tôi phần lớn các khối u gan có kích thước lớn có nhiều nhánh động mạch cả trong gan và ngoài gan cấp máu cho khối u do đó sử dụng tỷ lệ cồn tuyệt đối cao hơn (1:1) hiệu quả hơn trong việc kiểm soát nguồn cấp máu cho khối u.

Đau vùng gan sau khi TAELE là một triệu chứng phổ biến trong nghiên cứu của chúng tôi chiếm tỷ lệ $75,76 \%$. Chủ yếu là đau bụng nhe và vừa. Trong nghiên cứu của Gu (2010) cho thấy tỷ lệ đau xuất hiện ở tất cả các bệnh nhân, tuy nhiên không cho biết mức độ cũng như phương pháp xử trí [7].

\section{KẾT LUÂN}

Nồng độ $\mathrm{aFP}$ giảm dần sau 01 tháng và 03 tháng can thiệp. Sự giảm này là có ý nghĩa thống kê. Tỷ lệ đáp ứng điều trị nhóm u kích thước $\leq$ $10 \mathrm{~cm}$ cao hơn nhóm u kích thước $>10 \mathrm{~cm}$ ở thời điểm sau điều trị 01 tháng và 03 tháng, nhóm có tỷ lệ $\mathrm{E}: \mathrm{L}(1: 1)$ cao hơn nhóm có tỷ lệ 1:2. Sự khác biệt này có ý nghĩa thống kê. Điều trị UTBMTBG kích thước lớn $(\geq 7 \mathrm{~cm})$ bằng TAELE là một phương pháp an toàn và hiệu quả cần được nghiên cứu thêm để đánh giá đầy đủ.

\section{TÀI LIẸU THAM KHẢO}

1. Trịnh Văn Quang (2002). Những khối u gan. Bách khoa thư ung thư hoc. NXB Y học, 166-183.

2. Phùng Anh Tuấn. Nghiền cứu đặc điếm hình ảnh ung thư biểu mô tế bào gan trên chụp mạch số hóa xóa nền. Tạp chí Y dược học Quẩn sự. 2018:67-71.

3. Lê Anh Tuấn (2003). Đánh giá kết quả điều trị ung thư biểu mô tế bào gan bằng nút hoá chất động mạch gan. Luận văn tôt nghiệp bác sỹ nội trú.

4. Phạm Trung Dũng; Nguyễn Quang Duật; Vũ Văn Khiên. Tắc mạch hóa dầu và tắc mạch hóa chất sử dụng hạt vì cầu Dc-Beads. Tạp chí Y học Lâm sàng. 2019:46-53.

5. Dương Minh Thắng. Nghiên cứu điều trị ung thư biểu mô tế bào gan bằng phương pháp tắc mạch hóa dâu kết hợp với tiêm Ethanol qua da. 2008.

6. El Wakeel A, El Warraky M, Abd Ella T, El Safty M. Transarterial ethanol ablation of hepatocellular carcinoma with lipiodol-ethanol mixture. Menoufia Med J. 2016;29(2):285.

7. Gu YK, Luo RG, Huang JH, Tu QJS, Li XX, Gao F. Transarterial embolization ablation of hepatocellular carcinoma with a lipiodol-ethanol mixture. World J Gastroenterol. 2010;16(45):5766-5772.

8. Somma $F$, D'Angelo $R$, Serra N, Gatta G, Grassi R, Fiore F. Use of ethanol in the transarterial lipiodol embolization (TAELE) of intermediated-stage HCC: Is this safer than conventional trans-arterial chemo-embolization (cTACE)? PLOS One. 2015;10(6):1-13.

9. Yu SCH, Hui JWY, Hui EP, et al. Unresectable hepatocellular carcinoma: Randomized controlled trial of transarterial ethanol ablation versus transcatheter arterial chemoembolization. Radiology. 2014;270(2):607-620. 